\section{Excesso de mortes por causas respiratórias em oito metrópoles brasileiras durante os seis primeiros meses da pandemia de COVID-19}

\author{
Excess deaths from respiratory causes in eight \\ Brazilian metropolises during the first six \\ months of the COVID-19 pandemic
}

\section{Exceso de muertes por causas respiratorias en ocho metrópolis brasileñas durante los seis \\ primeros meses de la pandemia de COVID-19}

Jesem Douglas Yamall Orellana 1

Lihsieh Marrero 2

Bernardo Lessa Horta 3

\section{Resumo}

No Brasil, um dos países mais afetados pela pandemia de COVID-19, dados de mortalidade não refletem a real cifra de óbitos pela doença. O objetivo deste estudo é estimar o excesso de mortes por causas respiratórias e suas trajetórias durante os seis primeiros meses da epidemia de COVID-19, em adultos com 20 anos e mais de oito metrópoles regionais do Brasil. Estudo ecológico em que mortes por causas respiratórias (influenza, pneumonias, bronquites, outras doenças pulmonares obstrutivas crônicas, insuficiência respiratória aguda ou crônica, insuficiência respiratória ou transtorno respiratório não especificado e outras mortes codificadas com sintomas respiratórios) foram extraídas do Sistema de Informações sobre Mortalidade. Óbitos esperados foram estimados com modelos aditivos generalizados quasipoisson. Entre 23 de fevereiro e 8 de agosto de 2020, foram registradas 46.028 mortes por causas respiratórias nas oito cidades e excesso de 312\% (IC95\%: 304-321). Manaus (Amazonas), apresentou o maior excedente, 758\% (IC95\%: 668-858) e São Paulo o menor, 174\% (IC95\%: 164-183). Foi detectado precoce excesso nas Semanas Epidemiológicas (SE) 9-12 em Belém (Pará), Fortaleza (Ceará) e São Paulo. Em geral, o excesso de mortes, em termos relativos, foi maior dos 40-59 anos e em homens. A mortalidade excedente foi regionalmente heterogênea, com 2.463\% (IC95\%: 1.881-3.281) nas SE 17-20 em Manaus (Região Norte) e 808\% (IC95\%: 6121.059) nas SE 28-32 em Curitiba (Paraná, Região Sul). O elevado e heterogêneo percentual de mortes respiratórias excedentes sugere alta subnotificação de óbitos por COVID-19, reforça as desigualdades regionais e a necessidade de revisão das mortes associadas a sintomas respiratórios.

Mortalidade; COVID-19; Pobreza; Localização Geográfica

\author{
Correspondência \\ J. D. Y. Orellana \\ Instituto Leônidas e Maria Deane, Fundação Oswaldo Cruz. \\ Rua Teresina 476, 2o andar, sala 203, Manaus, AM 69057-070, \\ Brasil. \\ jesem.orellana@fiocruz.br \\ 1 Instituto Leônidas e Maria Deane, Fundação Oswaldo Cruz, \\ Manaus, Brasil. \\ 2 Universidade do Estado do Amazonas, Manaus, Brasil. \\ 3 Faculdade de Medicina, Universidade Federal de Pelotas, \\ Pelotas, Brasil.
}




\section{Introdução}

Segundo a Organização Mundial da Saúde (OMS), no final de janeiro de 2021 já haviam sido registrados aproximadamente 100 milhões de casos e 2,2 milhões de mortes pela COVID-19 no mundo. Em parte da Europa, a segunda onda da COVID-19, que inicialmente era uma ameaça 1, tornou-se uma dura realidade 2. Em 26 de janeiro de 2021, o Brasil, com cerca de 220 mil óbitos confirmados, foi superado apenas pelos Estados Unidos em número de mortes (OMS. https://covid19.who. int/, acessado em 26/Jan/2021) e os dados de mortalidade não refletem o real número de óbitos pela doença $3,4,5$.

As estratégias de testagem em massa e o acurado acompanhamento da evolução da epidemia têm sido um importante desafio em diversas regiões do planeta, em especial em países de baixa e média rendas, limitando o conhecimento de sua real magnitude 6,7,8,9. Os dados de mortalidade por COVID-19 são importantes tanto para o acompanhamento da evolução da pandemia como para garantir a qualidade de estimativas oriundas de estudos de modelagem 10,11. O conhecimento sobre as causas de morte baseia-se na Declaração de Óbito (DO) e, no caso de doença pela COVID-19, a recomendação é que a causa básica seja reportada como COVID-19, devendo a suspeita clínica sem resultados laboratoriais ser declarada como suspeita de COVID-19 12.

Devido à ampla variação na qualidade dos dados disponíveis, o excesso de óbitos tem sido usado como uma alternativa na avaliação da magnitude da pandemia 2,13. Cabe destacar que a avaliação do excesso de mortes em distintos contextos e ao longo do tempo não tem sido muito explorada e os poucos estudos disponíveis, em geral, foram realizados em países de alta renda, sendo que muitos focam na mortalidade geral 2 ou em mortes por causas naturais, como é o caso de alguns estudos brasileiros 5,14. Análises baseadas no excesso de mortes por causas respiratórias não apenas têm o potencial de auxiliar na melhoria das estatísticas vitais 15 como também no dimensionamento do impacto da pandemia, pois permite avaliar um conjunto de mortes potencialmente associadas ao novo coronavírus 4,16,17,18. O objetivo deste estudo é estimar o excesso de mortes por causas respiratórias durante os seis primeiros meses da epidemia de COVID-19, em adultos com 20 anos e mais de oito metrópoles regionais do Brasil.

\section{Material e método}

\section{Tipo de estudo e fontes de dados}

Estudo ecológico com abordagem temporal, baseado em dados das DO, extraídos do Sistema de Informações sobre Mortalidade (SIM) do Ministério da Saúde, para o período de 2015 a 2020. Os dados de 2015 a 2018 são considerados finalizados e os de 2019 (SIM. http://www2.datasus.gov.br/ DATASUS $/$ index.php?area $=0901 \&$ item $=1 \&$ acao $=26 \& \mathrm{pad}=31655$, acessado em $03 / \mathrm{Nov} / 2020$ ) estão integralizados e preliminarmente disponíveis. Já a versão mais atual dos dados de 2020 (SIM. http:// www2.datasus.gov.br/DATASUS/index.php?area $=0901 \& i$ tem $=1 \&$ acao $=26 \& p a d=31655$, acessado em 03/Nov/2020) foi disponibilizada pelo Ministério da Saúde no final de outubro, incluindo os registros da Semana Epidemiológica (SE) 44 (25-31 de outubro) provavelmente defasados, pois o prazo máximo para que as Secretarias Estaduais de Saúde façam a transferência dos dados para o módulo nacional do sistema é de até 60 dias após o encerramento do mês de ocorrência do óbito (SIM. http:// www2.datasus.gov.br/DATASUS/index.php?area $=0901 \& i t e m=1 \&$ acao $=26 \&$ pad $=31655$, acessado em 03/Nov/2020).

No intuito de garantir maior cobertura possível às análises de 2020, foram incluídos os óbitos com data de ocorrência até o fim da SE 32 (2-8 de agosto), já que os totais de mortes naturais do SIM, quando comparados aos do Registro Civil (Central de Informações do Registro Civil Nacional. https:// transparencia.registrocivil.org.br/especial-covid, acessado em 03/Nov/2020) que foram usados apenas como fonte de dados auxiliar, apresentavam diferença sempre próxima a 5\%. Exceto os óbitos com ocorrência nos primeiros dias de agosto, os dados incluídos neste estudo, em particular aqueles com encerramento no mês de julho, remetem a um período maior que 90 dias após a ocorrência dos mesmos, reduzindo assim a possibilidade de atraso nas notificações de mortes por COVID-19 19,20,21. 


\section{Cidades incluídas no estudo}

Foram incluídas oito metrópoles regionais, duas da Região Sudeste (Rio de Janeiro e São Paulo), duas da Região Nordeste (Fortaleza e Recife), duas da Região Norte (Manaus e Belém), uma da Região Centro-oeste (Cuiabá) e outra da Região Sul (Curitiba) do Brasil. Oficialmente, até a presente data, São Paulo, a maior metrópole brasileira, foi a cidade na qual o primeiro caso e óbito por COVID-19 do país foi notificado. O Rio de Janeiro, a segunda maior metrópole do país, foi a segunda cidade a notificar um óbito por COVID-19. Fortaleza e Recife foram as capitais mais afetadas pela epidemia na Região Nordeste, e Manaus e Belém foram as mais afetadas na Região Norte.

Considerando o acumulado de mortes notificadas por COVID-19 nas 26 capitais de estados, São Paulo concentrou o maior número absoluto de mortes, seguida por Rio de Janeiro, Fortaleza, Recife, Manaus e Belém (Ministério da Saúde. https://covid.saude.gov.br/, acessado em 03/Nov/2020). Já Cuiabá e Curitiba foram incluídas no estudo por serem as capitais com mais mortes nas regiões Centro-oeste e Sul, respectivamente. Até o fim da SE 32, as oito cidades incluídas concentravam aproximadamente $75 \%$ das mortes notificadas nas 26 capitais (Ministério da Saúde. https://covid.saude.gov. br/, acessado em 03/Nov/2020).

\section{Definições operacionais}

Devido à baixa frequência de mortes por COVID-19 em crianças e adolescentes no Brasil 5, as estimativas realizadas neste estudo consideram somente indivíduos com 20 anos ou mais.

Em detrimento das dificuldades inerentes à realização do diagnóstico etiológico acurado de infecções respiratórias agudas e virais 5 , especialmente em contexto pandêmico 6,10 , utilizamos as classificações de causa básica de óbito potencialmente relacionadas a estes desfechos 4,16,18. Nesse contexto, as mortes por causas respiratórias foram usadas como proxy das mortes associadas à infecção pelo novo coronavírus. Assim, segundo a Classificação Estatística Internacional de Doenças e Problemas Relacionados com a Saúde (CID-10) 22, o indicador de mortes respiratórias foi composto pelos registros com causa básica de óbito codificada como: influenza (J9-J11), pneumonias (J12-J18 e J22), bronquites (J40, J41 e J42) e outras doenças pulmonares obstrutivas crônicas (J44). Além desses códigos do capítulo X (Doenças do aparelho respiratório) da CID-10, foram incluídos no indicador de mortes respiratórias as causas de morte codificadas como insuficiência respiratória aguda (J960), insuficiência respiratória crônica (J961), insuficiência respiratória não especificada (J969), colapso pulmonar (J981) e transtorno respiratório não especificado (J989) 22.

Por fim, devido ao período pandêmico e à forte instabilidade da rede médico-hospitalar no Brasil, especialmente nos primeiros meses da epidemia 4,5,23,24, também foram considerados em nosso indicador de mortes respiratórias os registros com causa básica codificada como: tosse (R05), dispneia (R060), respiração ofegante (R062), respiração periódica (R063), outras anormalidades e as não especificadas da respiração (R068), códigos que compõem o capítulo XVIII (Sintomas, sinais e achados anormais de exames clínicos e de laboratório, não classificados em outra parte) da CID-10 22.

De acordo com a OMS, o excesso de mortes representa o número de mortes situado acima de um valor esperado, segundo um padrão de mortalidade previamente observado na população 18 .

Foram consideradas 24 SE, com início na SE 9 (23-29 de fevereiro de 2020), período em que ocorreu a notificação oficial do primeiro caso de COVID-19 no Brasil, e fim na SE 32 (2-8 de agosto de 2020), início da queda sustentada do número semanal de mortes por COVID-19 durante a primeira fase da epidemia no país (Ministério da Saúde. https:/covid.saude.gov.br/, acessado em 03/ Nov/2020). Portanto, o intervalo de tempo analisado correspondeu aos primeiros seis meses da epidemia de COVID-19 no Brasil. Esse período foi subdividido em seis intervalos (SE 9-12; SE 13-16; SE 17-20; SE 21-24; SE 25-28; e SE 29-32). 


\section{Análise de dados}

Para cada capital, os dados observados de mortalidade, oriundos do SIM, entre 2015 e 2019 nas SE consideradas foram utilizados para estimar o número de mortes esperadas nas SE selecionadas em 2020.

As estimativas de óbitos esperados em 2020 foram obtidas por meio de ajustes de modelos aditivos generalizados quasipoisson 25 com correção para sobredispersão. As variáveis faixa etária, sexo, período de SE e a interação destas variáveis com o ano de ocorrência foram consideradas como preditores nos respectivos modelos para cada cidade. $\mathrm{O}$ ano de ocorrência foi ajustado de forma não paramétrica (spline), no intuito de capturar possíveis tendências não lineares da mortalidade ao longo do período avaliado. Com base nos modelos ajustados, foi estimado o número de óbitos esperados de acordo com a faixa etária, o sexo e as SE consideradas em 2020, para cada uma das cidades analisadas.

A estimativa de excesso de mortes por causas respiratórias foi baseada no cálculo da razão entre o número observado e o esperado de óbitos, em um contexto sem a pandemia para o ano de 2020. De acordo com a OMS, a porcentagem de mortes em excesso pode ser mais compreensível para os tomadores de decisão 17 . Por isso, optamos por apresentar os resultados de excesso de óbitos em porcentagens, acompanhadas de seus respectivos intervalos de 95\% de confiança (IC95\%).

As análises foram efetuadas no software R, versão 3.6.1, e Rstudio, versão 1.2.1335 (http://www.rproject.org).

\section{Aspectos éticos}

O estudo foi realizado em conformidade com a Resolução no 466/2012 do Conselho Nacional de Saúde (CNS). Nesse caso, a aprovação por um Comitê de Ética em Pesquisa com Seres Humanos não foi necessária devido ao uso de dados não identificados e publicamente disponíveis.

\section{Resultados}

Entre 23 de fevereiro e 8 de agosto de 2020, foram registradas 46.028 mortes por causas respiratórias nas 8 capitais, sendo 12.264 em São Paulo, 13.025 no Rio de Janeiro, 6.585 em Fortaleza, 5.087 em Recife, 3.621 em Belém, 3.003 em Manaus, 1.275 em Curitiba e 1.168 em Cuiabá. Com base nos valores preditos para 2020, seriam esperados 11.160 óbitos por causas respiratórias nas 8 capitais, resultando em um excesso de mortes de 312\% (IC95\%: 304-321). O excesso de mortes foi maior em Manaus, 758\% (IC95\%: 668-858) e menor em São Paulo, 174\% (IC95\%: 164-183).

$\mathrm{O}$ excesso de mortes, em termos relativos, foi geralmente maior nos indivíduos com idades entre 40 e 59 anos e menor naqueles com 60 anos e mais e nas mulheres, embora esta diferença não tenha sido estatisticamente significativa em Recife, Curitiba e Cuiabá (Tabela 1).

$\mathrm{Na}$ análise estratificada, de acordo com o sexo e a faixa etária e para as capitais da Região Norte (Figura 1), observou-se excesso de mortes nas SE 9-12 em Belém, especialmente nas mulheres com 60 anos ou mais. Tanto em homens como em mulheres, durante o período analisado, o excesso de mortes foi mais expressivo nas SE 17-20. Além disso, observou-se excesso de mortes, em ambas as cidades, nas SE 29-32, especialmente nas faixas etárias de 40-59 e de 60 anos ou mais.

A Figura 2 mostra que durante o período analisado, na Região Nordeste, o excesso de mortes foi mais expressivo nas SE 17-20, independentemente do sexo, especialmente nas faixas etárias de 40-59 e de 60 anos ou mais. Além disso, observou-se excesso de mortes, em ambas as cidades, nas SE 29-32, independentemente da faixa etária e do sexo.

De acordo com a Figura 3, na Região Sudeste observou-se excesso de mortes nas SE 9-12 em São Paulo, especialmente nos homens com 60 anos ou mais. Independentemente do sexo e da faixa etária, em São Paulo, durante o período analisado, o excesso de mortes foi mais expressivo nas SE 21-24, e na cidade do Rio de Janeiro foi nas SE 17-20. Além disso, observou-se excesso de mortes em ambas as cidades nas SE 29-32.

Tanto em Curitiba como em Cuiabá, durante o período analisado, o excesso de mortes foi mais expressivo nas SE 29-32, especialmente entre os homens de 40-59 e de 60 anos ou mais (Figura 4). 
Tabela 1

Excesso de mortes por causas respiratórias em oito capitais selecionadas, de acordo com cidade, sexo, faixa etária e períodos de Semanas Epidemiológicas (SE). Brasil, 2020.

\begin{tabular}{|c|c|c|c|}
\hline Características & Observado/Esperado (n) & $\%$ & IC95\% \\
\hline \multicolumn{4}{|l|}{ Manaus } \\
\hline \multicolumn{4}{|l|}{ Faixa etária (anos) * } \\
\hline $20-39$ & $107 / 19$ & 463 & $246-817$ \\
\hline $40-59$ & $660 / 35$ & 1.786 & $1.242-2.549$ \\
\hline$\geq 60$ & $2.236 / 296$ & 655 & $569-753$ \\
\hline \multicolumn{4}{|l|}{ Sexo } \\
\hline Masculino & $1.909 / 179$ & 966 & $815-1.143$ \\
\hline Feminino & $1.094 / 171$ & 540 & $445-652$ \\
\hline \multicolumn{4}{|l|}{ Períodos (SE) } \\
\hline 9-12 (fevereiro/março) & $56 / 67$ & 0,84 & $0,59-19$ \\
\hline 13-16 (março/abril) & $416 / 61$ & 582 & $421-792$ \\
\hline 17-20 (abril/maio) & $1.538 / 60$ & 2.463 & $1.881-3.218$ \\
\hline 21-24 (maio/junho) & $613 / 61$ & 905 & $662-1.207$ \\
\hline 25-28 (junho/julho) & $233 / 52$ & 348 & $232-505$ \\
\hline 29-32 (julho/agosto) & $147 / 49$ & 200 & $117-315$ \\
\hline Total & $3.003 / 350$ & 758 & $668-858$ \\
\hline \multicolumn{4}{|l|}{ Belém } \\
\hline \multicolumn{4}{|l|}{ Faixa etária (anos) * } \\
\hline $20-39$ & $142 / 23$ & 517 & $297-859$ \\
\hline $40-59$ & $663 / 60$ & 1.105 & $748-1.339$ \\
\hline$\geq 60$ & $2.816 / 573$ & 391 & $349-438$ \\
\hline \multicolumn{4}{|l|}{ Sexo } \\
\hline Masculino & $2.182 / 298$ & 632 & $549-726$ \\
\hline Feminino & $1.439 / 358$ & 302 & $258-351$ \\
\hline \multicolumn{4}{|l|}{ Períodos (SE) } \\
\hline 9-12 (fevereiro/março) & $154 / 114$ & 35 & $6-72$ \\
\hline 13-16 (março/abril) & $270 / 134$ & 101 & $64-148$ \\
\hline 17-20 (abril/maio) & $1.847 / 123$ & 1.402 & $1.151-1.702$ \\
\hline 21-24 (maio/junho) & $827 / 110$ & 652 & $516-817$ \\
\hline 25-28 (junho/julho) & $294 / 89$ & 230 & $161-319$ \\
\hline 29-32 (julho/agosto) & $229 / 86$ & 166 & $108-241$ \\
\hline Total & $3.621 / 656$ & 452 & $408-500$ \\
\hline \multicolumn{4}{|l|}{ Fortaleza } \\
\hline \multicolumn{4}{|l|}{ Faixa etária (anos) * } \\
\hline $20-39$ & $248 / 21$ & 1.081 & $656-1.744$ \\
\hline $40-59$ & $1.140 / 83$ & 1.273 & $999-1.616$ \\
\hline$\geq 60$ & $5.197 / 742$ & 600 & $549-656$ \\
\hline \multicolumn{4}{|l|}{ Sexo } \\
\hline Masculino & $3.666 / 357$ & 927 & $821-1.045$ \\
\hline Feminino & $2.919 / 489$ & 497 & $442-557$ \\
\hline \multicolumn{4}{|l|}{ Períodos (SE) } \\
\hline 9-12 (fevereiro/março) & $186 / 144$ & 29 & $4-61$ \\
\hline 13-16 (março/abril) & $495 / 170$ & 191 & $145-247$ \\
\hline 17-20 (abril/maio) & $2.619 / 175$ & 1.397 & $1.184-1.644$ \\
\hline 21-24 (maio/junho) & $2.082 / 130$ & 1.502 & $1.241-1.812$ \\
\hline 25-28 (junho/julho) & $827 / 115$ & 619 & $492-774$ \\
\hline 29-32 (julho/agosto) & $376 / 112$ & 236 & $172-315$ \\
\hline Total & $6.585 / 846$ & 678 & $625-736$ \\
\hline
\end{tabular}

(continua) 
Tabela 1 (continuação)

\begin{tabular}{|c|c|c|c|}
\hline Características & Observado/Esperado (n) & $\%$ & IC95\% \\
\hline \multicolumn{4}{|l|}{ Recife } \\
\hline \multicolumn{4}{|l|}{ Faixa etária (anos) * } \\
\hline $20-39$ & $190 / 30$ & 533 & $331-831$ \\
\hline $40-59$ & $1.006 / 87$ & 1.056 & $829-1.339$ \\
\hline$\geq 60$ & $3.891 / 512$ & 660 & $593-733$ \\
\hline \multicolumn{4}{|l|}{ Sexo } \\
\hline Masculino & $2.669 / 326$ & 719 & $630-818$ \\
\hline Feminino & $2.418 / 303$ & 698 & $608-799$ \\
\hline \multicolumn{4}{|l|}{ Períodos (SE) } \\
\hline 9-12 (fevereiro/março) & $114 / 97$ & 18 & $0,90-54$ \\
\hline 13-16 (março/abril) & $337 / 105$ & 221 & $158-300$ \\
\hline 17-20 (abril/maio) & $1.734 / 123$ & 1.301 & $1.074-1.593$ \\
\hline 21-24 (maio/junho) & $1.432 / 105$ & 1.264 & $1.019-1.563$ \\
\hline 25-28 (junho/julho) & 779/109 & 615 & $485-773$ \\
\hline 29-32 (julho/agosto) & $691 / 90$ & 668 & $516-856$ \\
\hline Total & $5.087 / 629$ & 709 & $644-779$ \\
\hline \multicolumn{4}{|l|}{ São Paulo } \\
\hline \multicolumn{4}{|l|}{ Faixa etária (anos) * } \\
\hline $20-39$ & $416 / 94$ & 343 & $254-454$ \\
\hline $40-59$ & $2.145 / 501$ & 328 & $288-372$ \\
\hline$\geq 60$ & $9.703 / 3.889$ & 149 & $140-159$ \\
\hline \multicolumn{4}{|l|}{ Sexo } \\
\hline Masculino & $6.826 / 2.197$ & 211 & $196-296$ \\
\hline Feminino & $5.438 / 2.287$ & 138 & $126-150$ \\
\hline \multicolumn{4}{|l|}{ Períodos (SE) } \\
\hline 9-12 (fevereiro/março) & $738 / 608$ & 21 & $9-35$ \\
\hline 13-16 (março/abril) & $1.410 / 678$ & 108 & $90-128$ \\
\hline 17-20 (abril/maio) & $2.250 / 717$ & 214 & $189-241$ \\
\hline 21-24 (maio/junho) & $3.161 / 831$ & 280 & $252-311$ \\
\hline 25-28 (junho/julho) & $2.472 / 867$ & 185 & $164-208$ \\
\hline 29-32 (julho/agosto) & $2.233 / 783$ & 185 & $163-209$ \\
\hline Total & $12.264 / 4.484$ & 174 & $164-183$ \\
\hline \multicolumn{4}{|l|}{ Rio de Janeiro } \\
\hline \multicolumn{4}{|l|}{ Faixa etária (anos) * } \\
\hline $20-39$ & $402 / 91$ & 342 & $252-455$ \\
\hline $40-59$ & $2.303 / 360$ & 540 & $472-615$ \\
\hline$\geq 60$ & $10.320 / 3.236$ & 219 & $207-232$ \\
\hline \multicolumn{4}{|l|}{ Sexo } \\
\hline Masculino & $7.074 / 1.659$ & 326 & $304-350$ \\
\hline Feminino & $5.951 / 2.028$ & 193 & $179-209$ \\
\hline \multicolumn{4}{|l|}{ Períodos (SE) } \\
\hline 9-12 (fevereiro/março) & $518 / 502$ & 3 & $0,91-17$ \\
\hline 13-16 (março/abril) & $1.391 / 572$ & 143 & $121-168$ \\
\hline 17-20 (abril/maio) & $5.339 / 649$ & 723 & $658-792$ \\
\hline 21-24 (maio/junho) & $3.295 / 686$ & 380 & $342-421$ \\
\hline 25-28 (junho/julho) & $1.468 / 660$ & 122 & $103-144$ \\
\hline 29-32 (julho/agosto) & $1.014 / 618$ & 64 & $48-81$ \\
\hline Total & $13.025 / 3.687$ & 253 & $241-266$ \\
\hline
\end{tabular}

(continua) 
Tabela 1 (continuação)

\begin{tabular}{|c|c|c|c|}
\hline Características & Observado/Esperado (n) & $\%$ & IC95\% \\
\hline \multicolumn{4}{|l|}{ Curitiba } \\
\hline \multicolumn{4}{|l|}{ Faixa Etária (anos) * } \\
\hline $20-39$ & $41 / 12$ & 242 & $80-550$ \\
\hline $40-59$ & $238 / 30$ & 693 & $443-1.060$ \\
\hline$\geq 60$ & $996 / 309$ & 222 & $184-266$ \\
\hline \multicolumn{4}{|l|}{ Sexo } \\
\hline Masculino & $724 / 196$ & 269 & $215-333$ \\
\hline Feminino & $551 / 155$ & 255 & $197-325$ \\
\hline \multicolumn{4}{|l|}{ Períodos (SE) } \\
\hline 9-12 (fevereiro/março) & $33 / 38$ & 0,87 & $0,54-38$ \\
\hline 13-16 (março/abril) & $77 / 45$ & 71 & $18-147$ \\
\hline 17-20 (abril/maio) & $72 / 52$ & 38 & $0,97-98$ \\
\hline 21-24 (maio/junho) & $116 / 68$ & 71 & $26-130$ \\
\hline 25-28 (junho/julho) & $323 / 76$ & 325 & $231-446$ \\
\hline 29-32 (julho/agosto) & $654 / 72$ & 808 & $612-1.059$ \\
\hline Total & $1.275 / 351$ & 263 & $223-309$ \\
\hline \multicolumn{4}{|l|}{ Cuiabá } \\
\hline \multicolumn{4}{|l|}{ Faixa etária (anos) * } \\
\hline $20-39$ & $61 / 12$ & 408 & $174-844$ \\
\hline $40-59$ & $320 / 18$ & 1.678 & $1.106-2.758$ \\
\hline$\geq 60$ & $787 / 127$ & 520 & $414-647$ \\
\hline \multicolumn{4}{|l|}{ Sexo } \\
\hline Masculino & $710 / 87$ & 716 & $553-920$ \\
\hline Feminino & $458 / 70$ & 554 & $409-741$ \\
\hline \multicolumn{4}{|l|}{ Períodos (SE) } \\
\hline 9-12 (fevereiro/março) & $41 / 26$ & 58 & $0,96-58$ \\
\hline 13-16 (março/abril) & $35 / 26$ & 35 & $0,81-124$ \\
\hline 17-20 (abril/maio) & $38 / 29$ & 31 & $0,81-112$ \\
\hline 21-24 (maio/junho) & $135 / 26$ & 419 & $241-690$ \\
\hline 25-28 (junho/julho) & $448 / 25$ & 1.692 & $1.098-2.581$ \\
\hline 29-32 (julho/agosto) & $471 / 25$ & 1.784 & $1.160-2.717$ \\
\hline Total & $1.168 / 157$ & 644 & $530-779$ \\
\hline
\end{tabular}

Fonte: Departamento de Informática do SUS; Sistema de Informações sobre Mortalidade.

* Corresponde ao quantitativo das SE 9-32, no período de 23 de fevereiro a 8 de agosto de 2020. 


\section{Figura 1}

Óbitos observados, esperados e excesso de mortes por causas respiratórias em 2020, de acordo com grupos de Semanas Epidemiológicas (SE), sexo e faixa etária, Manaus e Belém (Região Norte), Brasil.

1a) Manaus: masculino, 20-39 anos

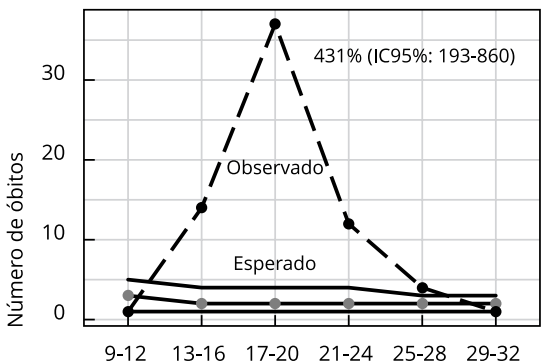

1d) Manaus: feminino, 20-39 anos

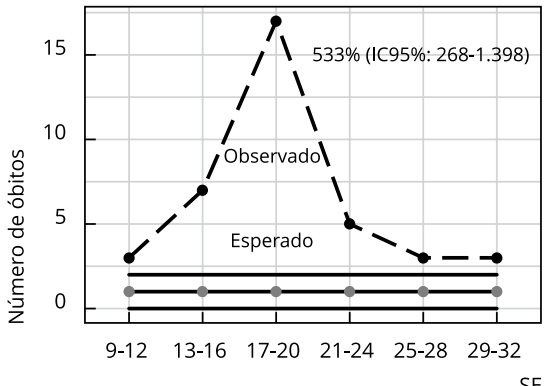

1g) Belém: masculino, 20-39 anos

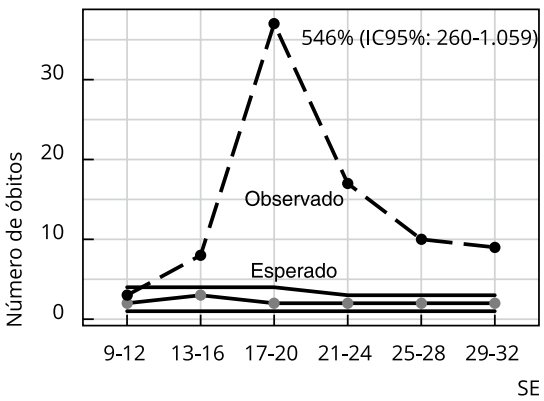

1j) Belém: feminino, 20-39 anos

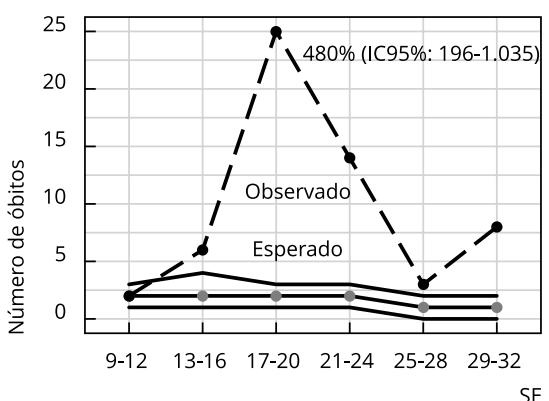

1b) Manaus: masculino, 40-59 anos

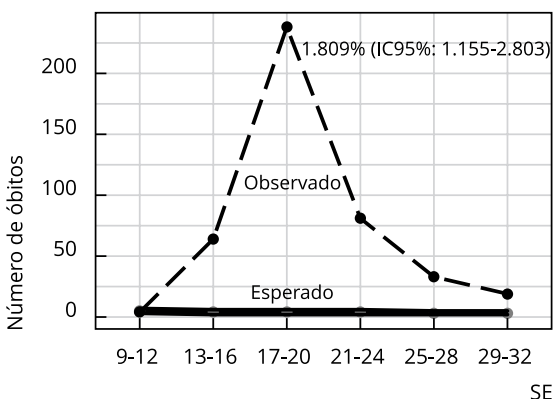

1e) Manaus: feminino, 40-59 anos

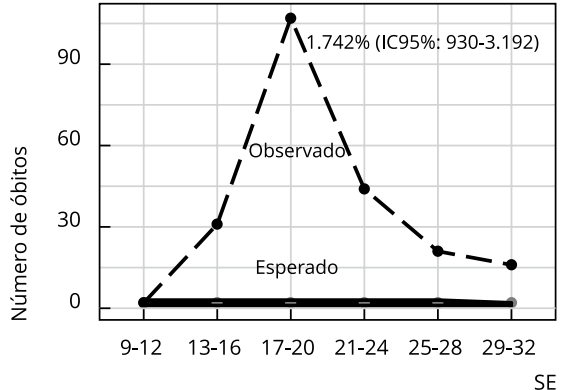

1h) Belém: masculino, 40-59 anos

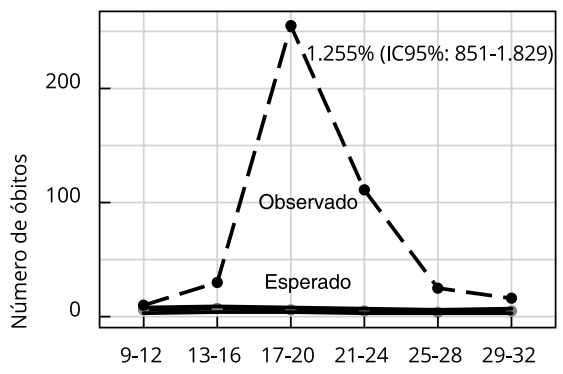

1k) Belém: feminino, 40-59 anos

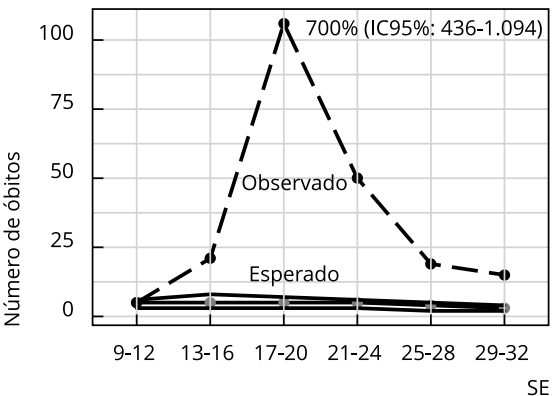

1c) Manaus: masculino, $60+$ anos

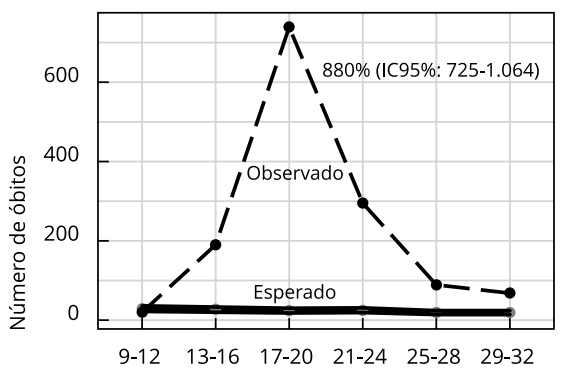

SE

1f) Manaus: feminino $60+$ anos

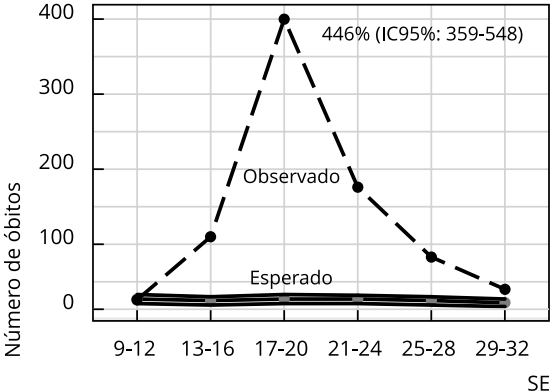

1i) Belém: masculino, $60+$ anos

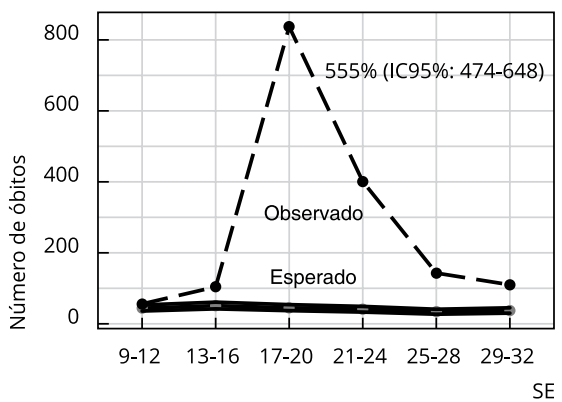

1) Belém: feminino, 60+ anos

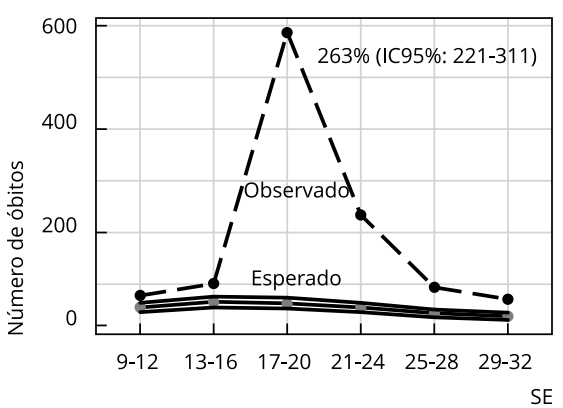

Fonte: Departamento de Informática do SUS; Sistema de Informações sobre Mortalidade. 


\section{Figura 2}

Óbitos observados, esperados e excesso de mortes por causas respiratórias em 2020, de acordo com grupos de Semanas Epidemiológicas (SE), sexo e faixa etária, Fortaleza e Recife (Região Nordeste), Brasil.

2a) Fortaleza: masculino, 20-39 anos

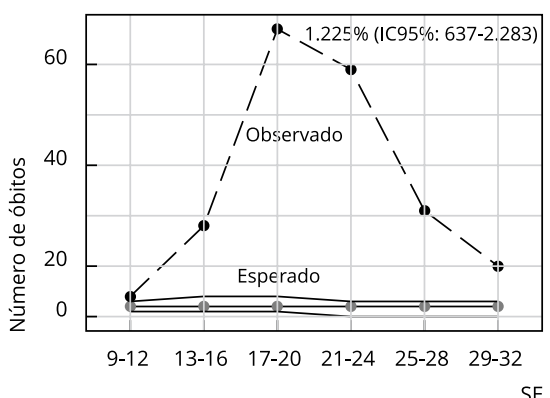

2d) Fortaleza: feminino, 20-39 anos

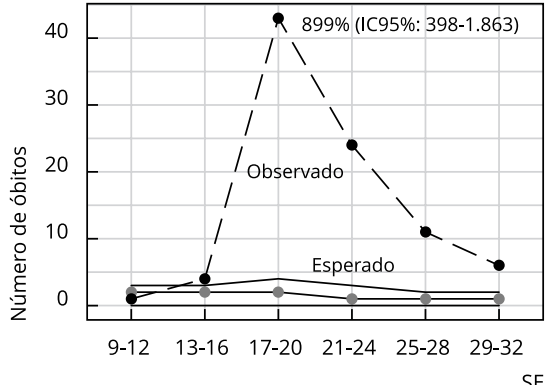

2g) Recife: masculino, 20-39 anos

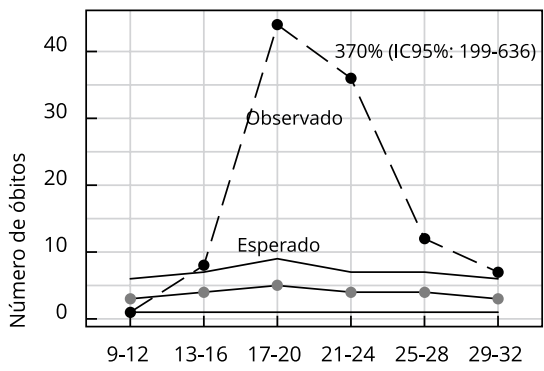

SE

2j) Recife: feminino, 20-39 anos

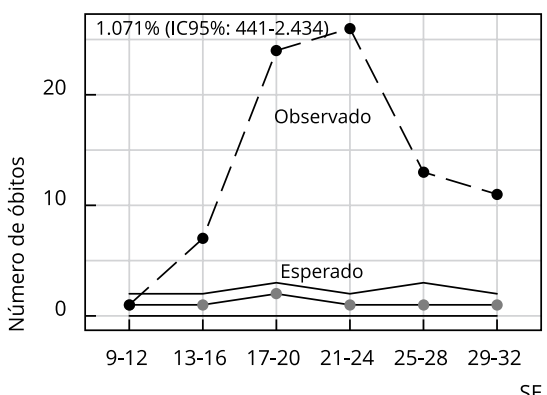

2b) Fortaleza: masculino, 40-59 anos

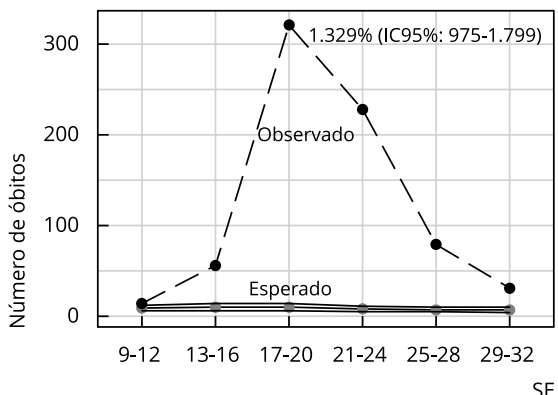

2e) Fortaleza: feminino, 40-59 anos

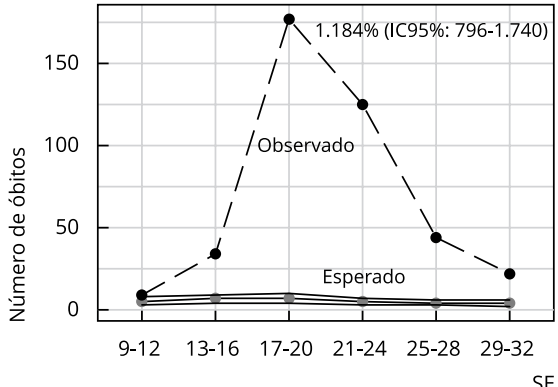

2h) Recife: masculino, 40-59 anos

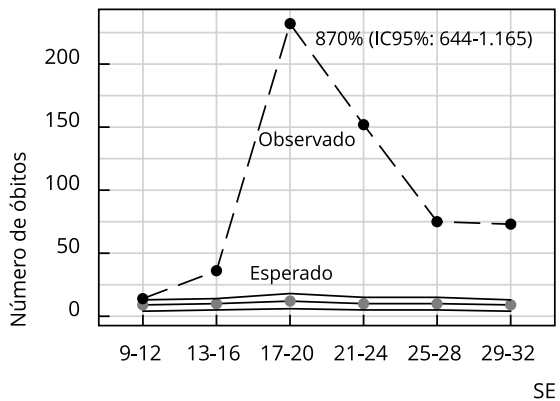

2k) Recife: feminino, 40-59 anos

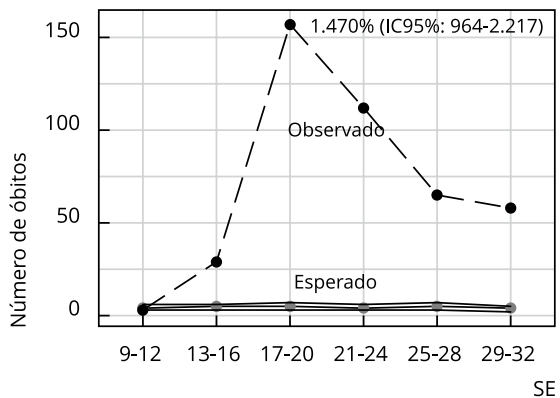

2c) Fortaleza: masculino, 60+ anos

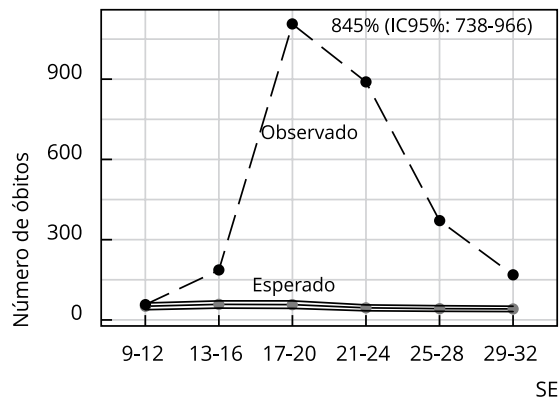

2f) Fortaleza: feminino $60+$ anos

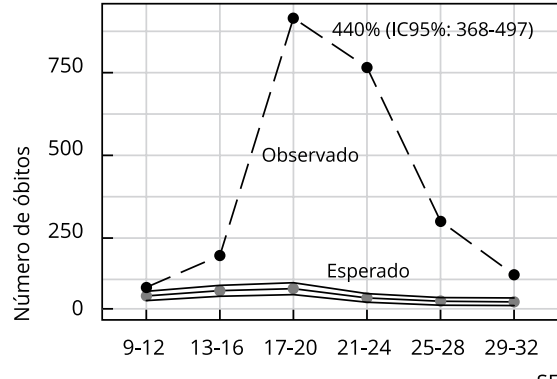

2i) Recife: masculino, $60+$ anos

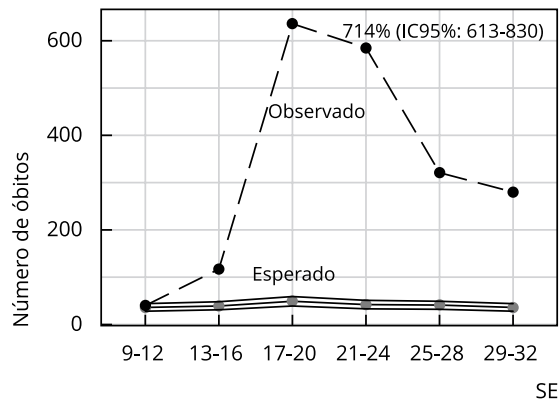

21) Recife: feminino, $60+$ anos

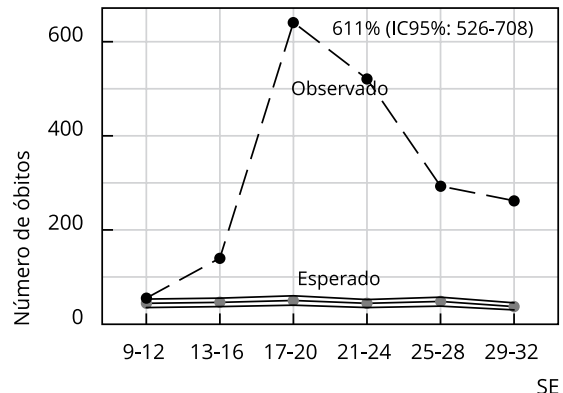

Fonte: Departamento de Informática do SUS; Sistema de Informações sobre Mortalidade. 


\section{Figura 3}

Óbitos observados, esperados e excesso de mortes por causas respiratórias em 2020, de acordo com grupos de Semanas Epidemiológicas (SE), sexo e faixa etária, São Paulo e Rio de Janeiro (Região Sudeste), Brasil.

3a) São Paulo: masculino, 20-39 anos

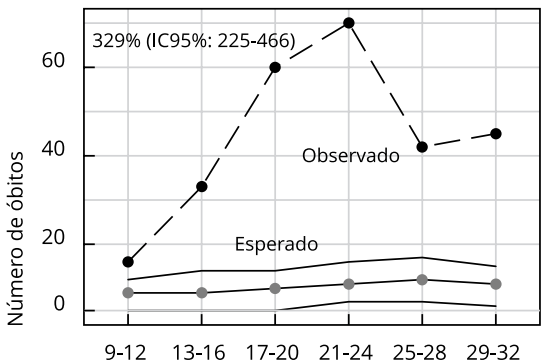

SE

3d) São Paulo: feminino, 20-39 anos

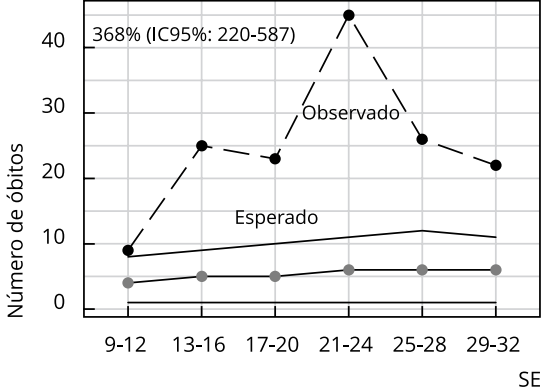

3g) Rio de Janeiro: masculino, 20-39 anos

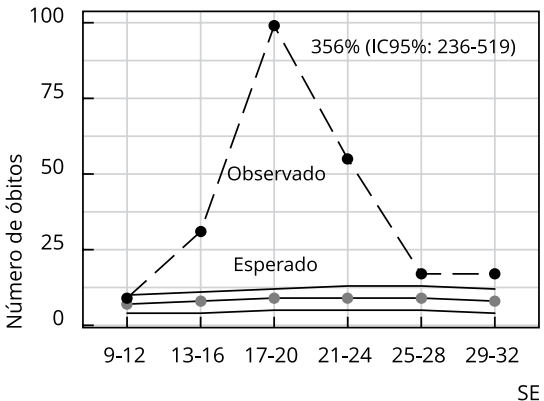

3j) Rio de Janeiro: feminino, 20-39 anos

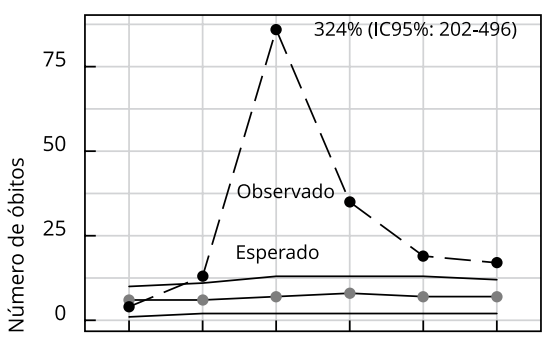

$\begin{array}{llllll}9-12 & 13-16 & 17-20 & 21-24 & 25-28 & 29-32\end{array}$ 3b) São Paulo: masculino, 40-59 anos

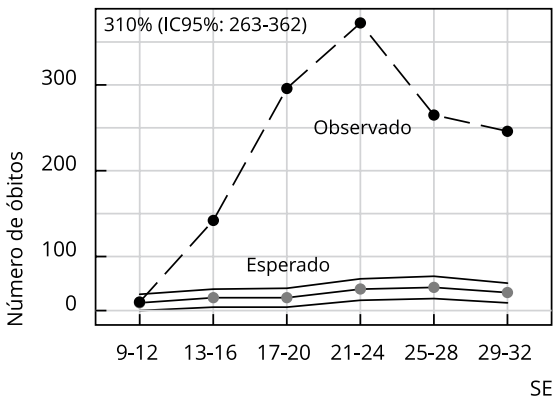

3e) São Paulo: feminino, 40-59 anos

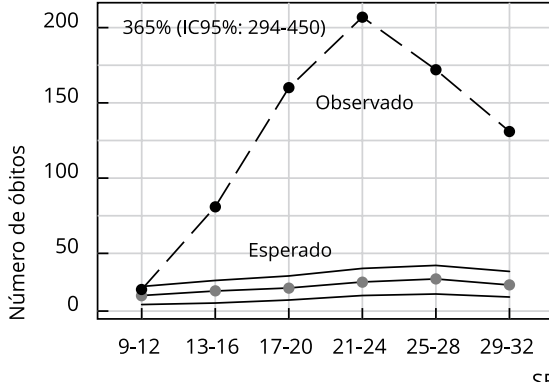

3h) Rio de Janeiro: masculino, 40-59 anos

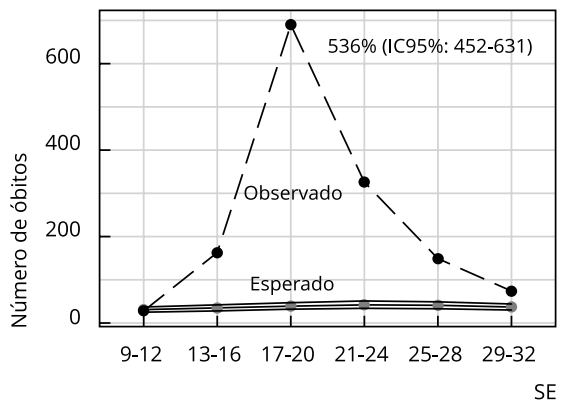

3k) Rio de Janeiro: feminino, 40-59 anos

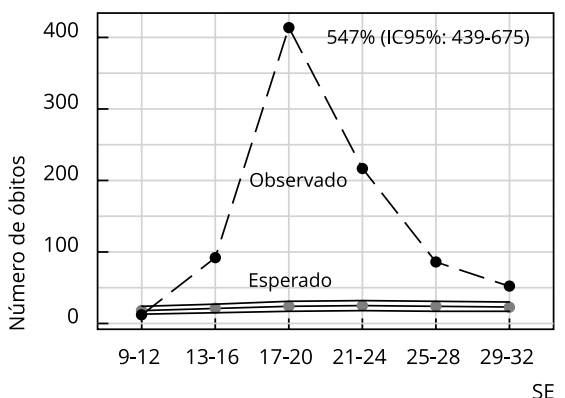

3c) São Paulo: masculino, 60+ anos

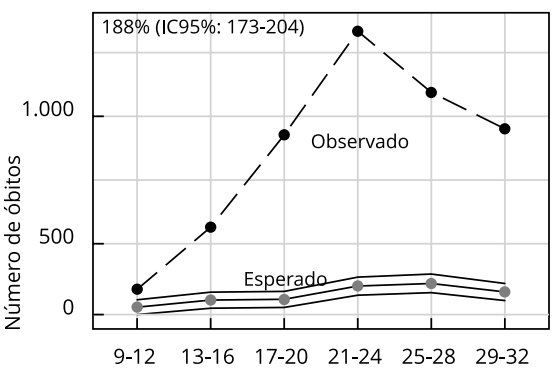

SE

3f) São Paulo: feminino $60+$ anos

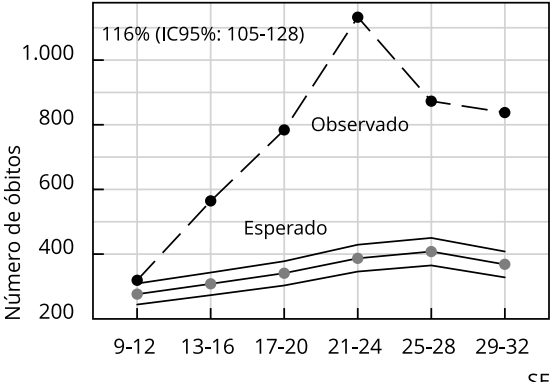

3i) Rio de Janeiro: masculino, $60+$ anos

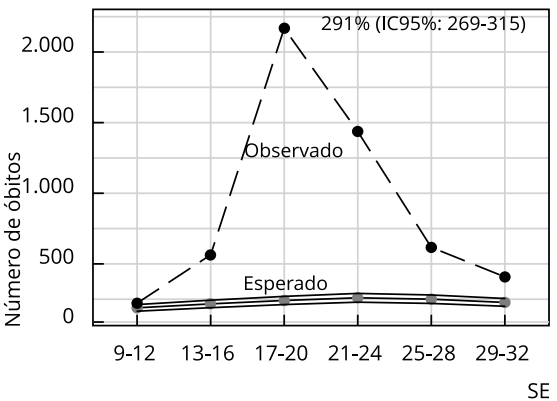

31) Rio de Janeiro: feminino, $60+$ anos

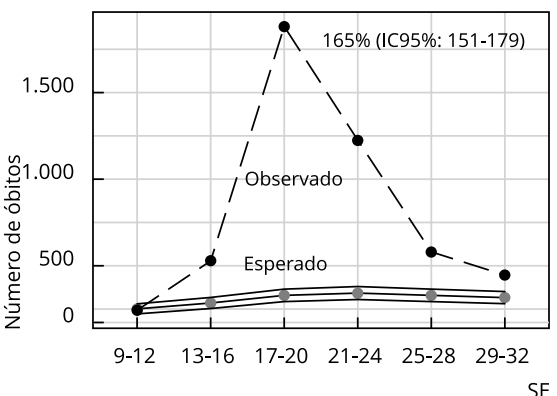

Fonte: Departamento de Informática do SUS; Sistema de Informações sobre Mortalidade. 


\section{Figura 4}

Óbitos observados, esperados e excesso de mortes por causas respiratórias em 2020, de acordo com grupos de Semanas Epidemiológicas (SE), sexo e faixa etária, Curitiba (Região Sul) e Cuiabá (Região Centro-oeste), Brasil.

4a) Curitiba: masculino, 20-39 anos

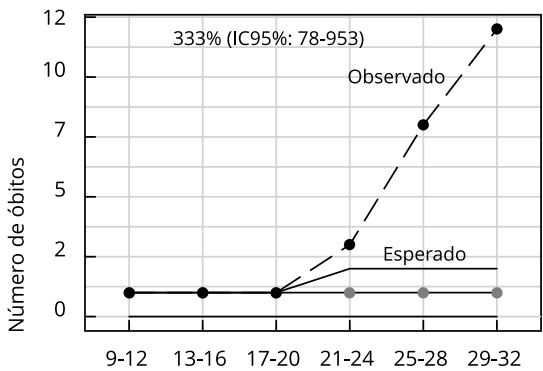

4d) Curitiba: feminino, 20-39 anos

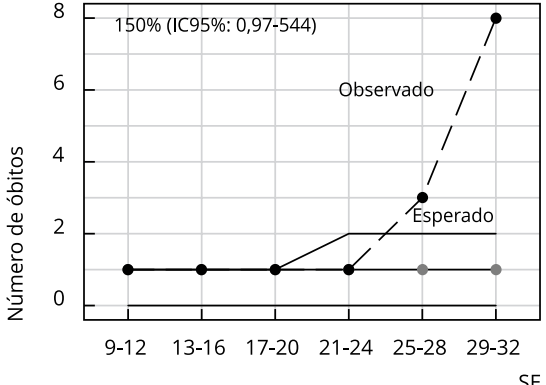

4g) Cuiabá: masculino, 20-39 anos

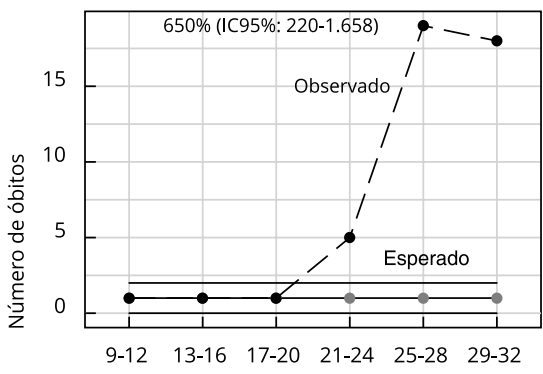

SE

4j) Cuiabá: feminino, 20-39 anos

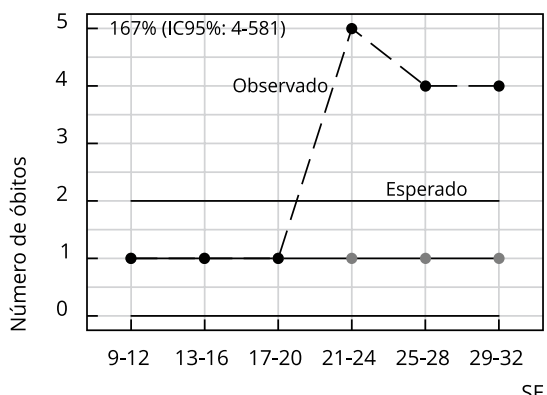

4b) Curitiba: masculino, 40-59 anos

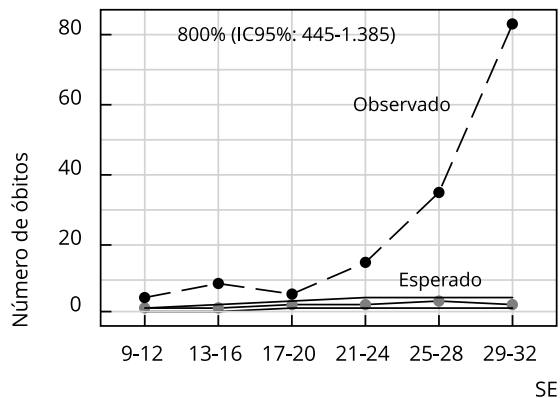

4e) Curitiba: feminino, 40-59 anos

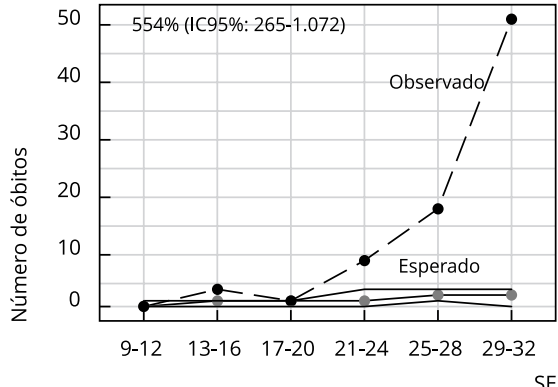

4h) Cuiabá: masculino, 40-59 anos

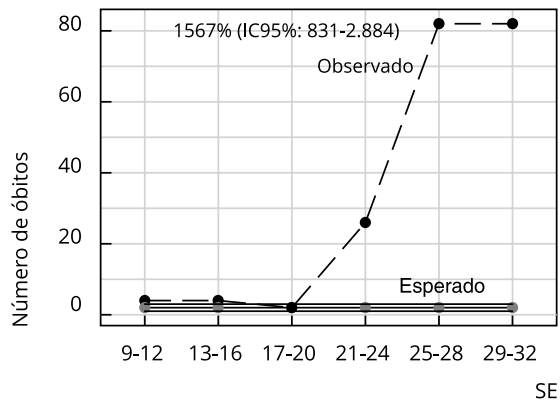

4k) Cuiabá: feminino, 40-59 anos

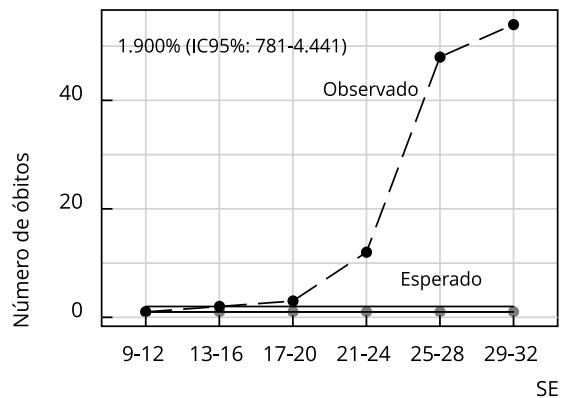

4c) Curitiba: masculino, $60+$ anos

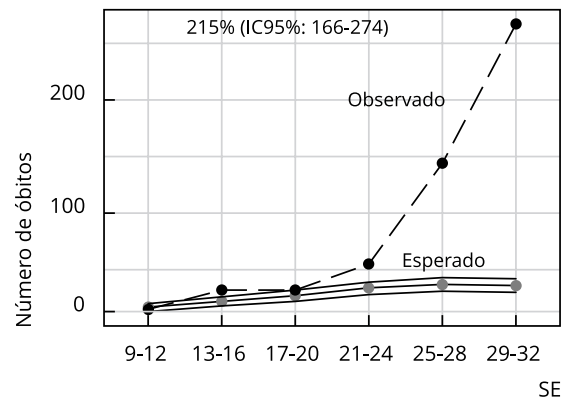

4f) Curitiba: feminino $60+$ anos

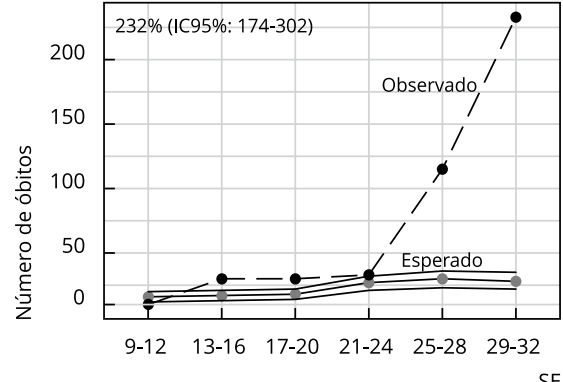

4i) Cuiabá: masculino, $60+$ anos

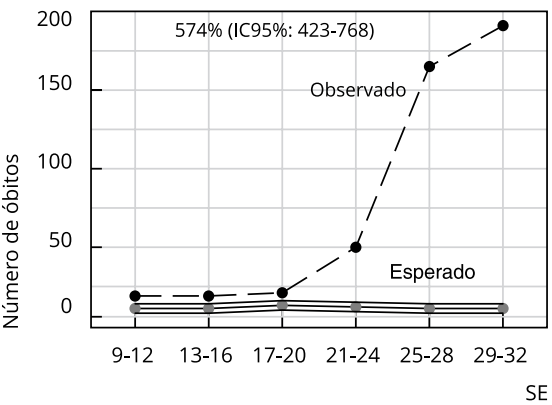

4) Cuiabá: feminino, 60+ anos

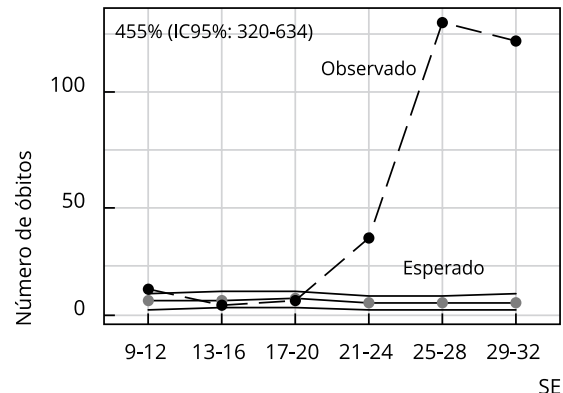

Fonte: Departamento de Informática do SUS; Sistema de Informações sobre Mortalidade. 


\section{Discussão}

Nossas estimativas indicam $312 \%$ de mortes excedentes por causas respiratórias e ampla variação nos percentuais das oito cidades avaliadas, sobretudo naquelas das regiões Norte e Nordeste do Brasil. Ademais, a trajetória das mortes excedentes nos primeiros seis meses de epidemia foi geograficamente heterogênea, com indicativos de maior mortalidade excedente em momentos mais precoces no Norte, em comparação às regiões Sudeste e Sul do país.

Chamou atenção o considerável excesso de mortes por causas respiratórias nas SE 9-12 em Belém (Região Norte), Fortaleza (Região Nordeste) e São Paulo (Região Sudeste). Até o fim das SE 9-12, o Ministério da Saúde havia notificado apenas 18 mortes por COVID-19 em todo o país 26. No entanto, os dados mais atuais, para esse mesmo período, indicam 32 mortes por COVID-19 somente em São Paulo, nenhuma em Belém e quatro em Fortaleza, adicionando mais indícios acerca da subnotificação de mortes por COVID-19 no Brasil, sobretudo na fase inicial da epidemia.

Entre as mortes confirmadas por COVID-19 em Fortaleza, duas tiveram como data de ocorrência os dias 13 e 14 de fevereiro e, uma terceira, o dia 20 de fevereiro (dados não apresentados). Portanto, ao contrário do que se acreditava até novembro de 2020 e caso as datas presumidas estejam corretas, a notificação do primeiro óbito por COVID-19 no Brasil e, consequentemente, a ocorrência do primeiro caso, não necessariamente coincidem com as datas oficiais, 12 de março e 25 de fevereiro de 20205. Hipótese semelhante seria igualmente plausível para a cidade de ocorrência desses eventos, pois dados do próprio Ministério da Saúde indicam que eles não necessariamente ocorreram em São Paulo.

É preciso destacar que Fortaleza, cidade brasileira mais próxima da Europa e que até fevereiro de 2020 tinha voos diretos para França, Holanda, Espanha e Estados Unidos 27, ostentava o status de principal centro de conexões aéreas do Nordeste com o restante do Brasil. Ademais, é possível que o padrão de mobilidade humana local 28,29 tenha sido consideravelmente alterado a partir de 24 de janeiro, início do pré-Carnaval na cidade e de grande fluxo de turistas para a região litorânea do Estado do Ceará, o que pode ter favorecido a introdução do novo coronavírus, sem descartar o eventual papel de visitantes oriundos do exterior 30, como Espanha, França e Itália que já tinham casos de COVID-19 confirmados desde janeiro de 2020 (OMS. https://covid19.who.int/, acessado em 26/ $\mathrm{Jan} / 2021$ ) 31. Além disso, é oportuno destacar que assim como observado em outras regiões do Brasil, a elite socioeconômica pode ter contribuído consideravelmente para que o novo coronavírus migrasse para áreas mais pobres e, portanto, socioeconomicamente mais vulneráveis 32 .

Ao contrário do esperado, mas em linha com os resultados de um estudo realizado em dois estados da Índia 33, nossas estimativas de mortes excedentes por idade mostram que a faixa etária de 40 a 59 anos, em termos relativos, foi a mais afetada, independentemente da cidade. Inicialmente, acreditavase que a pandemia de COVID-19 seria mais branda em países considerados de baixa e média rendas, cuja estrutura etária é mais jovem do que a de países de alta renda (Ministério da Saúde. http://tabnet. datasus.gov.br/cgi/deftohtm.exe?popsvs/cnv/popbr.def, acessado em 03/Nov/2020) 34. No entanto, recentes evidências apontam que a composição demográfica da população explica em parte, mas não toda a heterogeneidade da mortalidade associada ao novo coronavírus 9,21,35,36.

Em Manaus, Belém, Fortaleza, São Paulo e Rio de Janeiro, o excesso de mortes por causas respiratórias, em termos relativos, foi maior entre os homens, principalmente nos indivíduos com 60 anos e mais, assim como observado em outros países que também apontam maior mortalidade em homens 37,38 .

Nas quatro cidades das regiões Norte e Nordeste, o período predominante para o maior excesso de mortes por causas respiratórias foi nas SE 17-20. No entanto, durante as SE 29-32, quase seis meses depois da notificação do primeiro caso de COVID-19 no Brasil, observou-se um expressivo excesso de mortes, sugerindo transmissão comunitária elevada e prolongada nessas cidades, especialmente em Manaus que apresentou um padrão explosivo no excesso de mortes durante a primeira onda da epidemia 5,23,24,39.

Embora Belém, Fortaleza e Recife tenham adotado lockdown em maio, semanas depois do pico epidêmico de abril (InfoGripe. https://gitlab.procc.fiocruz.br/mave/repo/-/tree/master/Boletins\%20 do\%20InfoGripe/Imagens/Capitais, acessado em 03/Nov/2020), a sua implantação parece ter tido impacto favorável sobre a diminuição do número de casos novos e de mortes devido à COVID-19 40, o que pode ter limitado percentuais de mortes excedentes ainda maiores nas semanas seguintes. 
Nas duas cidades da Região Sudeste, o momento de maior mortalidade excedente divergiu não apenas temporalmente, mas em intensidade. No Rio de Janeiro, observou-se maior mortalidade excedente nas SE 17-20, que foi acompanhada de expressivas e sequenciais reduções daí em diante. Já em São Paulo, observou-se maior mortalidade excedente nas SE 21-24 e, em comparação ao valor mais expressivo do Rio de Janeiro nas SE 17-20, projetou-se com intensidade 160\% menor, seguida por estabilidade no excesso de mortes daí em diante. Portanto, os excedentes de mortes respiratórias em São Paulo foram não só expressivamente menores do que os observados no Rio de Janeiro, como também em relação ao padrão observado nas demais cidades incluídas neste estudo. Ainda que ambas as cidades não tenham adotado lockdown, é possível que essas diferenças estejam relacionadas aos diferentes padrões de resposta à epidemia. São Paulo, por exemplo, adotou precocemente importantes medidas de restrição à circulação de pessoas 29,41. Além disso, contava com amplos recursos médico-hospitalares e assistenciais, quando comparada às demais capitais avaliadas neste estudo, os quais foram reforçados em 2020 durante a pandemia de COVID-19 42,43.

Por outro lado, tanto em Curitiba, situada na Região Sul, como em Cuiabá, na Região Centro-oeste, o momento de maior excesso de mortes por causas respiratórias foi mais tardio do que nas outras cidades e regiões do país, ocorrendo nas SE 29-32. Em Curitiba, o momento mais agudo do excesso de mortes foi semelhante ao da cidade do Rio de Janeiro, embora mais tardio. É possível que esse fenômeno esteja relacionado com a menor circulação do novo coronavírus nos três primeiros meses da epidemia em Curitiba, já que a maior taxa de incidência de síndrome respiratória aguda grave (SRAG) nesse período não superou o valor de 9 para cada 100 mil habitantes, uma das menores entre todas as capitais do Brasil até então. Daí em diante, essa incidência aumentou até dobrar e atingir o seu valor mais alto no final de junho (InfoGripe. https://gitlab.procc.fiocruz.br/mave/repo/-/tree/ master/Boletins\%20do\%20InfoGripe/Imagens/Capitais, acessado em 03/Nov/2020), justamente no momento que antecedeu às SE 29-32, marcado pelo mais expressivo excesso de mortes por causas respiratórias.

Embora se reconheça o efeito da sazonalidade sobre a circulação de alguns vírus que agravam o perfil de morbimortalidade de populações 44 e os valores preditos de mortes por causas respiratórias para Curitiba tenham aumentado consideravelmente durante as SE 25-32, período que coincide com as baixas temperaturas de junho e julho 45 , não parece sensato atribuir, exclusivamente, a variáveis climáticas o expressivo aumento no excesso de mortes por causas respiratórias em Curitiba nesse período 46 .

Em Cuiabá, embora o valor mais expressivo do excesso de mortes também tenha sido tardio, em comparação às outras cidades incluídas no estudo, ocorrendo nas SE 29-32, observou-se que a intensidade desse evento foi mais próxima do padrão das cidades do Norte/Nordeste. O exame da curva de incidência para SRAG mostra que até as SE 17-20 o excesso de mortes foi pouco expressivo em Cuiabá, o que também pode estar relacionado com a menor circulação do novo Coronavírus nos dois primeiros meses da epidemia, já que a taxa de incidência de SRAG só começou a aumentar fortemente a partir das SE 21-24 (InfoGripe. https://gitlab.procc.fiocruz.br/mave/repo/-/tree/master/ Boletins\%20do\%20InfoGripe/Imagens/Capitais, acessado em 03/Nov/2020), coincidindo com o aumento mais agudo do excesso de mortes por causas respiratórias.

Observou-se um desproporcional excesso de mortes por causas respiratórias nas cidades do Norte/Nordeste e em Cuiabá (Centro-oeste) em comparação às cidades das regiões Sudeste e Sul, além de importante heterogeneidade quanto ao momento de maior excesso de mortes, reforçando as diferenças previamente apontadas em um estudo soroepidemiológico 8 e de modelagem, que estimou as mudanças no número efetivo de reprodução do SARS-CoV-2 (coronavírus da síndrome respiratória aguda grave 2) e sua relação com a mobilidade humana no Brasil 29.

Um estudo realizado em Estocolmo (Suécia), sugere que condições propiciadoras da propagação viral, como viver em áreas caracterizadas por um status socioeconômico mais baixo e com populações mais jovens, estiveram associadas ao excesso de mortalidade durante a pandemia de COVID-19 36. Esses resultados reforçam que a existência de diferentes gradientes de mortalidade por COVID-19 entre os países e regiões 47 é algo relativamente comum, independentemente do nível de desenvolvimento socioeconômico. No caso do Brasil, a carga de doenças é geralmente maior nos estados das regiões Norte e Nordeste do que nas regiões Sul e Sudeste 48. Além disso, a expectativa de vida saudável 49 , bem como o nível de desenvolvimento humano, costumam ser menos desfavoráveis nas regiões Sudeste e Sul do Brasil 24. 
Nosso estudo tem algumas limitações como o fato de não ter sido possível avaliar um banco de dados com codificação das causas de mortes para os anos de 2019 e, sobretudo, 2020, finalizado por parte do Ministério da Saúde, o que permitiria redistribuição de causas de morte para todo o período de análise. É provável que tenha ocorrido o sub-registro de óbitos, especialmente para 2020, devido ao eventual atraso na finalização dos dados. No entanto, a comparação entre o total de óbitos de 2020 do SIM do Ministério da Saúde e o observado no Registro Civil, ligado ao Ministério da Justiça, sugere que essa distorção pode ser pequena. Diferenças quanto à cobertura e qualidade do SIM, além de questões operacionais da vigilância epidemiológica, podem ter influenciado a magnitude das diferenças observadas no excesso de óbitos entre as cidades avaliadas. Ademais, como se trata de uma base de dados preliminar, é possível que não somente codificações mudem de classificação como também eventuais correções nas datas de ocorrência dos óbitos.

Como pontos fortes do nosso estudo, destacamos o uso do excesso de mortes 13 por causas respiratórias como uma proxy do impacto da pandemia de COVID-19 mais informativa do que o tradicional indicador de mortalidade geral para óbitos excedentes ou mesmo o de mortes naturais. Isso se aplica, em particular, em cenário de ampla incerteza quanto à real magnitude da mortalidade específica por COVID-19, especialmente em países de baixa e média rendas onde os desafios para a adequada codificação da causa básica de morte são ainda maiores 6,10. Cabe destacar que nossos resultados não retratam a epidemia em um único momento do tempo, mas a sua dinâmica ao longo dos primeiros seis meses da epidemia de COVID-19 em diferentes cidades e regiões do Brasil.

O expressivo excesso de mortes por causas respiratórias, de certa forma, já era esperado 7,10 devido ao conhecido problema da baixa e pouco eficiente testagem para o novo coronavírus no país 4 , especialmente em regiões metropolitanas onde a epidemia se comportou de forma mais agressiva e a resposta local foi fraca, como em Manaus, Belém, Fortaleza e na cidade do Rio de Janeiro 3,5,29,39.

Os resultados deste estudo sugerem que o indicador de mortes excedentes por causas respiratórias é uma importante alternativa não só para auxiliar no dimensionamento do real impacto da epidemia de COVID-19 e sua evolução em diferentes contextos, mas também para alertar sobre a necessidade de aperfeiçoamento de sistemas de informações sobre mortalidade e para o adequado planejamento de ações voltadas à mitigação da pandemia.

Ademais, acreditamos que seria prudente as autoridades sanitárias e pesquisadores investirem na revisão das causas de mortes associadas a sintomas respiratórios, com maior atenção aos primeiros meses da pandemia 5 e em regiões sabidamente mais afetadas ou com menor tradição em vigilância epidemiológica e laboratorial. 


\section{Colaboradores}

J. D. Y. Orellana participou da concepção do estudo, coleta e interpretação dos dados, redação e revisão final do manuscrito. L. Marrero participou da redação, interpretação dos dados e revisão final do manuscrito. B. L. Horta participou da concepção do estudo, redação, interpretação dos dados e revisão final do manuscrito.

\section{Referências}

1. Wise J. Covid-19: risk of second wave is very real, say researchers. BMJ 2020; 369:m2294.

2. Nørgaard SK, Vestergaard LS, Nielsen J, Richter L, Schmid D, Bustos N, et al. Real-time monitoring shows substantial excess all-cause mortality during second wave of COVID-19 in Europe, October to December 2020. Euro Surveill 2021; 26:2002023.

3. Andrade R. Covid-19 is causing the collapse of Brazil's national health service. BMJ 2020; 370:m3032.

4. França EB, Ishitani LH, Teixeira RA, Abreu DMX, Corrêa PRL, Marinho F, et al. Deaths due to Covid-19 in Brazil: how many are there and which are being identified? Rev Bras Epidemiol 2020; 23:e200053.

5. Orellana JDY, Cunha GM, Marrero L, Moreira RI, Leite IC, Horta BL. Excesso de mortes durante a pandemia de COVID-19: subnotificação e desigualdades regionais no Brasil. Cad Saúde Pública 2021; 37:e00259120.

6. Xie X, Zhong Z, Zhao W, Zheng C, Wang F, Liu J. Chest CT for typical 2019-nCoV pneumonia: relationship to negative RT-PCR testing. Radiology 2020; 296:E41-5.

7. Carrillo-Larco RM. COVID-19 data sources in Latin America and the Caribbean. Travel Med Infect Dis 2020; 38:101750.

8. Hallal PC, Hartwig FP, Horta BL, Silveira MF, Struchiner CJ, Vidaletti LP, et al. SARS-CoV-2 antibody prevalence in Brazil: results from two successive nationwide serological household surveys. Lancet Glob Health 2020;8:e1390-8.

9. O’Driscoll M, Santos GR, Wang L, Cummings DA, Azman AS, Paireau J, et al. Age-specific mortality and immunity patterns of SARSCoV-2. Nature 2021; 590:140-5.

10. Lau H, Khosrawipour T, Kocbach P, Ichii H, Bania J, Khosrawipour V. Evaluating the massive underreporting and undertesting of COVID-19 cases in multiple global epicenters. Pulmonology 2021; 27:110-5.

11. Jewell NP, Lewnard JA, Jewell BL. Predictive mathematical models of the COVID-19 pandemic: underlying principles and value of projections. JAMA 2020; 323:1893-4.

12. Rao C. Medical certification of cause of death for COVID-19. Bull World Health Organ 2020; 98:298-A.

\section{Informações adicionais}

ORCID: Jesem Douglas Yamall Orellana (00000002-5607-2615); Lihsieh Marrero (0000-00022856-5682); Bernardo Lessa Horta (0000-00019843-412X).

13. Setel P, AbouZahr C, Atuheire EB, Bratschi $\mathrm{M}$, Cercone E, Chinganya O, et al. Mortality surveillance during the COVID-19 pandemic. Bull World Health Organ 2020; 98:374.

14. Silva GA, Jardim BC, Santos CVB. Excesso de mortalidade no Brasil em tempos de COVID-19. Ciênc Saúde Colet 2020; 25:3345-54.

15. Rossetto EV, Luna EJA. Database linkage for surveillance of the influenza A (H1N1) pdm09 pandemic in Brazil, 2009-2010. Cad Saúde Pública 2016; 32:e00014115.

16. Alonso WJ, Viboud C, Simonsen L, Hirano EW, Daufenbach LZ, Miller MA. Seasonality of influenza in Brazil: a traveling wave from the Amazon to the subtropics. Am J Epidemiol 2007; 165:1434-42.

17. World Health Organization. Revealing the toll of COVID-19: a technical package for rapid mortality surveillance and epidemic response. https://www.who.int/publications/i/item/re vealing-the-toll-of-covid-19 (acessado em 03/ Nov/2020).

18. Salciccioli JD, Marshall DC, Shalhoub J, Maruthappu M, De Carlo G, Chung KF. Respiratory disease mortality in the United Kingdom compared with EU15+ countries in 1985-2015: observational study. BMJ 2018; $363: k 4680$.

19. Observatório COVID-19 BR. Análises comentadas. https://covid19br.github.io/analises. html?aba=aba2 (acessado em 03/Nov/2020).

20. Ferreira C, Lachos A, Prates MO, Schumacher FL. A robust nonlinear mixed-effects model for COVID-19 death data. Statistics and Its Interface 2020; 14:49-57.

21. Sornette D, Mearns E, Schatz M, Wu K, Darcet D. Interpreting, analysing and modelling COVID-19 mortality data. Nonlinear Dyn 2020; [Online ahead of print].

22. Centro Colaborador da OMS para a Classificação de Doenças em Português. Classificação Estatística Internacional de doenças e problemas relacionados à Saúde. 10a Revisão (CID-10). São Paulo: Edusp; 2000.

23. Lemos DRQ, D’Angelo SM, Farias LABG, Almeida MM, Gomes RG, Pinto GP, et al. Health system collapse 45 days after the detection of COVID-19 in Ceará, Northeast Brazil: a preliminary analysis. Rev Soc Bras Med Trop 2020; 53:e20200354. 
24. Brant LCC, Nascimento BR, Teixeira RA, Lopes MACQ, Malta DC, Oliveira GMM, et al. Excess of cardiovascular deaths during the COVID-19 pandemic in Brazilian capital cities. Heart 2020; 106:1898-905.

25. Hastie TJ, Tibshirani RJ. Generalized additive models. London: Chapman and Hall; 1990.

26. Secretaria de Vigilância em Saúde, Ministério da Saúde. Doença pelo Coronavírus 2019. Boletim Epidemiológico 2020; (8). https://an tigo.saude.gov.br/images/pdf/2020/April/09/ be-covid-08-final-2.pdf (acessado em 03/ Nov/2020).

27. Governo do Estado do Ceará. Fortaleza recebe voo inaugural de Madri e se consolida como HUB aéreo. https://www.ceara.gov. $\mathrm{br} / 2019 / 12 / 21 /$ fortaleza-recebe-voo-inaugu ral-de-madri-e-se-consolida-como-hub-ae $\mathrm{reo} /$ (acessado em 03/Nov/2020).

28. Chang S, Pierson E, Koh PW, Gerardin J, Redbird B, Grusky D, et al. Mobility network models of COVID-19 explain inequities and inform reopening. Nature 2021; 589:82-7.

29. Candido DS, Claro IM, de Jesus JG, Souza WM, Moreira FRR, Dellicour S, et al. Evolution and epidemic spread of SARS-CoV-2 in Brazil. Science 2020; 369:1255-60.

30. Wells CR, Sah P, Moghadas SM, Pandey A, Shoukat A, Wang Y, et al. Impact of international travel and border control measures on the global spread of the novel 2019 coronavirus outbreak. Proc Natl Acad Sci U S A 2020; 117:7504-9

31. Stoecklin SB, Rolland P, Silue Y, Mailles A, Campese C, Simondon A, et al. First cases of coronavirus disease 2019 (COVID-19) in France: surveillance, investigations and control measures, January 2020. Euro Surveill 2020; 25:2000094.

32. Guimarães C. O vírus do preconceito. Revista POLI: Saúde, Educação e Trabalho 2020; 74:613.

33. Laxminarayan R, Wahl B, Dudala SR, Gopal K, Neelima S, Reddy KJ, et al. Epidemiology and transmission dynamics of COVID-19 in two Indian states. Science 2020; 370:691-7.

34. Travassos GF, Coelho AB, Arends-Kuenning MP. The elderly in Brazil: demographic transition, profile, and socioeconomic condition. Rev Bras Estud Popul 2020; 37:e0129.

35. Vestergaard LS, Nielsen J, Richter L, Schmid D, Bustos N, Braeye T, et al. Excess all-cause mortality during the COVID-19 pandemic in Europe - preliminary pooled estimates from the EuroMOMO network, March to April 2020. Euro Surveill 2020; 25:2001214.

36. Calderón-Larrañaga A, Vetrano DL, Rizzuto D, Bellander T, Fratiglioni L, Dekhtyar S. High excess mortality in areas with young and socially vulnerable populations during the COVID-19 outbreak in Stockholm Region, Sweden. BMJ Glob Health 2020; 5:e003595.
37. Jin J-M, Bai P, He W, Wu F, Liu X-F, Han D-M, et al. Gender differences in patients with COVID-19: Focus on severity and mortality. Frontiers in Public Health 2020; 8:152.

38. Beck DB, Aksentijevich I. Susceptibility to severe COVID-19. Science 2020; 370:404-5.

39. Aschwanden $C$. The false promise of herd immunity for COVID-19. Nature 2020; 587:268.

40. Silva L, Figueiredo Filho D, Fernandes A. The effect of lockdown on the COVID-19 epidemic in Brazil: evidence from an interrupted time series design. Cad Saúde Pública 2020; 36:e00213920.

41. Cruz CHB. Social distancing in São Paulo State: demonstrating the reduction in cases using time series analysis of deaths due to COVID-19. Rev Bras Epidemiol 2020; 23:e200056.

42. Noronha KVMS, Guedes GR, Turra CM, Andrade MV, Botega L, Nogueira D, et al. Pandemia por COVID-19 no Brasil: análise da demanda e da oferta de leitos hospitalares e equipamentos de ventilação assistida segundo diferentes cenários. Cad Saúde Pública 2020; 36:e00115320.

43. Croda JHR, Garcia LP. Immediate health surveillance response to COVID-19 epidemic. Epidemiol Serv Saúde 2020; 29:e2020002.

44. Mello WA, Paiva TM, Ishida MA, Benega MA, Santos MC, Viboud C, et al. The dilemma of influenza vaccine recommendations when applied to the tropics: the Brazilian case examined under alternative scenarios. PLoS One 2009; 4:e5095.

45. Trombetta H, Faggion HZ, Leotte J, Nogueira MB, Vidal LR, Raboni SM. Human coronavirus and severe acute respiratory infection in Southern Brazil. Pathog Glob Health 2016; 110:113-8

46. Mecenas P, Bastos RT da RM, Vallinoto ACR, Normando D. Effects of temperature and humidity on the spread of COVID-19: a systematic review. PLoS One 2020; 15:e0238339.

47. Ioannidis JP. Global perspective of COVID-19 epidemiology for a full-cycle pandemic. Eur J Clin Invest 2020; 50:e13423.

48. Machado DB, Pescarini JM, Ramos D, Teixeira R, Lozano R, Moura Pereira VO, et al. Monitoring the progress of health-related sustainable development goals (SDGs) in Brazilian states using the Global Burden of Disease indicators. Popul Health Metr 2020; 18:7.

49. Szwarcwald CL, de Souza Júnior PRB, Marques AP, de Almeida W da S, Montilla DER. Inequalities in healthy life expectancy by Brazilian geographic regions: findings from the National Health Survey, 2013. Int J Equity Health 2016; 15:141. 
Abstract

In Brazil, one of the countries most heavily affected by the COVID-19 pandemic, mortality data fail to reflect the real number of deaths from the disease. The study aimed to estimate excess deaths from respiratory causes and their trends during the first six month of the COVID-19 epidemic in adults 20 years or older in eight regional metropolises in Brazil. In this ecological study, deaths from respiratory causes (influenza, pneumonias, bronchitis, other chronic obstructive pulmonary diseases, acute or chronic respiratory failure, respiratory failure or respiratory disorder not otherwise specified, and other deaths coded with respiratory symptoms) were extracted from the Mortality Information System. Expected deaths were estimated with quasi-Poisson generalized additive models. From February 23 to August 8, 2020, 46,028 deaths from respiratory causes were recorded in the eight cities, with an excess of 312\% (95\%CI: 304-321). Manaus (Amazonas State), presented the highest excess, with 758\% (95\% CI: 668-858) and São Paulo the lowest, with 174\% (95\%CI: 164-183). Early excess mortality was detected in Epidemiological Weeks (EW) 9-12 in Belém (Pará State), Fortaleza (Ceará State), and São Paulo. In general, excess mortality was relatively higher in the 40-59-year age bracket and in men. Excess mortality was regionally heterogeneous, with 2,463\% (95\%CI: 1,881-3,281) in EW 17-20 in Manaus (North Region) and 808\% (95\%CI: 6121,059) in EW 28-32 in Curitiba (Paraná State, South Region). The high and heterogeneous percentage of excess respiratory deaths suggests high underreporting of COVID-19 deaths, which highlights regional inequalities and the need for revision of deaths associated with respiratory symptoms.

Mortality; COVID-19; Poverty; Geohraphic Locations

\section{Resumen}

En Brasil, uno de los países más afectados por la pandemia de COVID-19, los datos de mortalidad no reflejan la cifra real de fallecimientos por la enfermedad. El objetivo de este estudio es estimar el exceso de muertes por causas respiratorias $y$ sus trayectorias durante los seis primeros meses de la epidemia de COVID-19, en adultos con 20 años y más de ocho metrópolis regionales de Brasil. Estudio ecológico donde las muertes por causas respiratorias (gripe, neumonías, bronquitis, otras enfermedades pulmonares obstructivas crónicas, insuficiencia respiratoria aguda o crónica, insuficiencia respiratoria o trastorno respiratorio no especificado y otras muertes codificadas con sintomas respiratorios) fueron extraídas del Sistema de Información sobre Mortalidad. Los óbitos esperados fueron estimados con modelos generalizados aditivos casi-Poisson. Entre el 23 de febrero y el 8 de agosto de 2020, se registraron 46.028 muertes por causas respiratorias en las ocho ciudades $y$ un exceso de 312\% (IC95\%: 304-321). Manaos (Amazonas) presentó el mayor excedente, un $758 \%$ (IC95\%: 668-858) y São Paulo el menor, un 174\% (IC95\%: 164-183). Se detectó un exceso precoz en las Semanas Epidemiológicas (SE) 9-12 en Belém (Pará), Fortaleza y São Paulo. En general, el exceso de muertes, en términos relativos, fue mayor de los 40-59 años y en hombres. La mortalidad excedente fue regionalmente heterogénea, con 2.463\% (IC95\%: 1.881-3.281) en las SE 17-20 en Manaos (Región Norte) y un 808\% (IC95\%: 612-1.059) en las SE 28-32 en Curitiba (Paraná, Región Sur). El elevado y heterogéneo porcentaje de muertes respiratorias excedentes sugiere un alto subregistro de óbitos por COVID-19, refuerza las desigualdades regionales y la necesidad de revisión de las muertes asociadas a sintomas respiratorios.

Mortalidad; COVID-19; Pobreza; Ubicaciones Geográficas
Recebido em 23/Nov/2020

Versão final reapresentada em 25/Jan/2021

Aprovado em 19/Fev/2021 